\title{
BMJ Open Is health impact assessment useful in the context of trade negotiations? A case study of the Trans Pacific Partnership Agreement
}

\author{
Katherine Hirono, ${ }^{1}$ Fiona Haigh, ${ }^{1}$ Deborah Gleeson, ${ }^{2}$ Patrick Harris, ${ }^{3}$ \\ Anne Marie Thow, ${ }^{3}$ Sharon Friel $^{4}$
}

To cite: Hirono K, Haigh F, Gleeson D, et al. Is health impact assessment useful in the context of trade negotiations? A case study of the Trans Pacific Partnership Agreement. BMJ Open 2016;6:e010339.

doi:10.1136/bmjopen-2015010339

- Prepublication history for this paper is available online. To view these files please visit the journal online (http://dx.doi.org/10.1136/ bmjopen-2015-010339).

Received 22 October 2015 Revised 9 February 2016 Accepted 29 February 2016

\section{CrossMark}

For numbered affiliations see end of article.

Correspondence to Katherine Hirono; k.hirono@unsw.edu.au

\section{ABSTRACT}

Objective: The Trans Pacific Partnership Agreement (TPP) is a recently concluded free trade agreement involving Australia and 11 other Pacific-rim nations, which has the potential for far-reaching impacts on public health. A health impact assessment (HIA) was carried out during the negotiations to determine the potential future public health impact in Australia and to provide recommendations to mitigate potential harms. This paper explores the findings and outcomes of the $\mathrm{HIA}$, and how this approach can be used to provide evidence for public health advocacy.

Design: A modified version of the standard HIA process was followed. The HIA was led by technical experts in HIA, trade policy, and health policy, in collaboration with advocacy organisations concerned with the TPP and health. The HIA reviewed the provisions in leaked TPP text in order to determine their potential impact on future health policy. As part of this process, researchers developed policy scenarios in order to examine how TPP provisions may affect health policies and their subsequent impact to health for both the general and vulnerable populations. The four policy areas assessed were the cost of medicines, tobacco control, alcohol control and food labelling.

Results: In all areas assessed, the HIA found that proposed TPP provisions were likely to adversely affect health. These provisions are also likely to more adversely affect the health of vulnerable populations. Conclusions: The HIA produced relevant evidence that was useful in advocacy efforts by stakeholders, and engaging the public through various media platforms.

\section{INTRODUCTION}

It is increasingly recognised in the international health literature, that free trade agreements (FTAs), when not well designed, can have detrimental impacts on population health. $^{1-3}$ Trade agreements regulate the flow of goods, services and technologies between countries. Traditionally, an FTA is

\section{Strengths and limitations of this study}

- We conducted a health impact assessment (HIA) on the proposed Trans Pacific Partnership Agreement.

- We used scenario development to enable assessment of the proposed agreement.

- The HIA was used to engage health organisations in the public discourse about the trade negotiation process.

- As trade documents were secret, we relied on leaked drafts of the text.

an agreement between two or more countries, which aims to remove barriers to trade, such as tariffs or import quotas to member countries. Increasingly, FTAs have shifted to encompass not just the regulations related to the exchange of goods and services but also to rules regarding intellectual property and investment, and 'behind-the-border' regulation in many different sectors. ${ }^{4}$

The Trans Pacific Partnership Agreement (TPP) is an FTA set to become the largest regional trade agreement to date, potentially covering $36.3 \%$ of world GDP. ${ }^{5}$ It includes 12 Pacific-rim nations: Australia, Brunei, Canada, Chile, Japan, Malaysia, Mexico, New Zealand, Peru, Singapore, USA and Vietnam. At the time of writing, negotiations have concluded, and the final text has been publicly released, but the agreement has not yet been signed or ratified by any participating state.

The negotiation process of FTAs is usually confidential. This was the case in the TPP negotiations. The public (and public health professionals) had limited information and no access to draft texts (with the exception of leaks of a small number of chapters). Many concerns have been raised by national and international health and development organisations about the potential for the 
TPP to impact on public health. ${ }^{16-9}$ These include reduced access to affordable medicines, reduced effectiveness of tobacco and alcohol policies, reduced food security and poorer nutrition, increased costs of providing public health services, and pressure on the physical environment. Therefore, decisions were being made in the negotiations that have far-reaching population health impacts, but without input from the public.

There is growing interest in the use of health impact assessment (HIA) as a tool for analysing and informing global economic policies. ${ }^{3} 10$ The WHO Commission on Social Determinants of Health recommended that HIAs be undertaken on global economic agreements. ${ }^{11}$ HIA has been demonstrated to be effective in influencing planning and policymaking both within and outside the health sector, and is recognised as playing an important role in achieving healthy public policy. ${ }^{12-15}$ Many countries use HIA to evaluate the potential health consequences of a wide array of proposals that span different sectors and levels of government. ${ }^{16-19}$ The method thus has potential for informing trade policymaking from a health policy perspective.

A robust HIA process engages policy-relevant actors in articulating health-related concerns, develops concrete suggestions for policy formulation, and can be used to underpin evidence-based health-focused advocacy. ${ }^{20}$ All these are influential factors in policymaking, and particularly, agenda setting. ${ }^{21-23}$ HIA has been established as a useful process for public policymaking that can identify future health and equity impacts of policies, and is useful for brokering knowledge between researchers and policymakers. ${ }^{24}$ Likewise, it provides both a technical document that can be useful for decision-makers, while also tactically engaging with stakeholders who may use the results of an HIA in their own advocacy efforts. $^{3} 24$

Despite the recognised utility of HIA to inform decision-making, it is unclear to what extent HIAs can serve a role in informing the negotiation of FTAs in the context of limited access to information.

This paper reports on the process and findings of a HIA conducted on the TPP during its negotiation. We use the experience of conducting the HIA to reflect on the utility of the HIA method for prospectively assessing the likely health impact of a trade agreement that is negotiated under conditions of confidentially.

\section{MATERIALS AND METHODS}

We adapted standard HIA methodology (figure 1) to identify the potential health impacts of the TPP. A small working group comprised mainly of HIA experts led the process. A technical committee comprised of 12 public health experts (including experts on trade agreements and the specific health policy areas under investigation) supported the working group and provided feedback on the research, scope, analysis, findings and

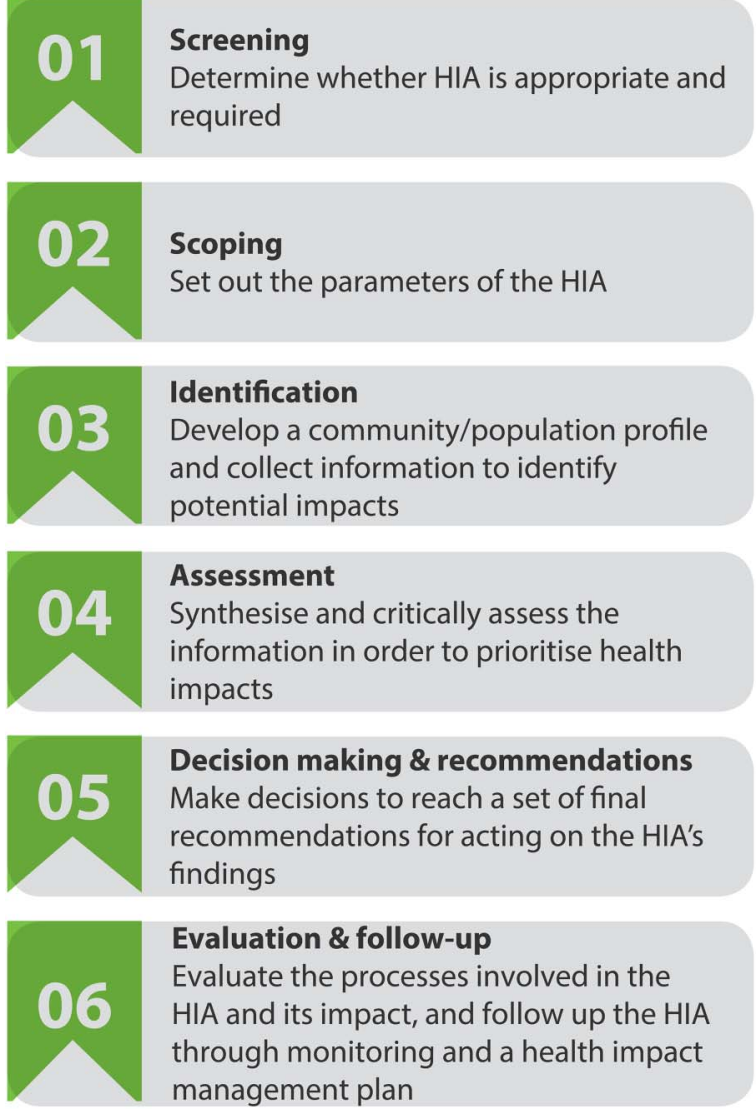

Figure 1 Health impact assessment (HIA) steps.

recommendations. An advocacy advisory committee comprised of 14 civil society organisations (see Acknowledgements) supported the HIA process and used HIA findings to inform their work in the area. Members of both groups provided advice and access to evidence to inform the HIA.

\section{Step 1: screening}

Screening identifies whether an HIA is possible or useful. A team of researchers convened in December 2013 to explore how HIA could be used to inform the TPP negotiation process in Australia. HIAs can be carried out at different depths ranging from desktop assessments using already available evidence, to comprehensive assessment that involves collecting and analysing data from multiple sources requiring significant time and resources. ${ }^{25}$ Given the uncertain time frame of the negotiation process along with resource constraints and limits to the accessibility of information about the TPP provisions under discussion, it was decided to conduct an intermediate HIA, which relied primarily on secondary data from the existing literature supported by expert input. As there was little opportunity for direct input to the trade negotiations, it was decided to use the HIA to inform advocates engaged with the TPP.

\section{Step 2: scoping}

Scoping sets out the parameters of the HIA. The TPP HIA was faced with the difficulty of predicting impacts 


\begin{tabular}{|c|c|c|}
\hline $\begin{array}{c}\text { Chapter/ } \\
\text { negotiating } \\
\text { area** }\end{array}$ & $\begin{array}{l}\text { Likely contents (based on leaked drafts, informed } \\
\text { commentary and/or previous trade agreements) }\end{array}$ & Possible health implications \\
\hline $\begin{array}{l}\text { Intellectual } \\
\text { property (IP)* }\end{array}$ & $\begin{array}{l}\text { Includes a set of obligations for countries to implement in their } \\
\text { domestic laws to protect intellectual property, including patents, } \\
\text { trademarks and copyright. Proposed provisions of particular } \\
\text { concern included patenting of minor variations to existing } \\
\text { products, patent term extensions, and longer monopolies on } \\
\text { the use of clinical trial data, particularly for biologic products. }\end{array}$ & $\begin{array}{l}\text { - Longer and broader monopolies on new medicines } \\
\text { and other health technologies, delaying the market } \\
\text { entry of cheaper alternatives. } \\
\text { - Protection of other types of IP such as trademarks } \\
\text { (e.g. on cigarette packaging). }\end{array}$ \\
\hline Transparency & $\begin{array}{l}\text { Transparency provisions generally involve requirements to } \\
\text { provide notice and publish information about policy and } \\
\text { administrative changes, and to provide review and appeal } \\
\text { mechanisms. } \\
\text { An annex* to the Transparency Chapter includes a specific set } \\
\text { of provisions for pharmaceutical pricing and reimbursement } \\
\text { schemes like Australia's Pharmaceutical Benefits Scheme (PBS). } \\
\text { Provisions in a draft US proposal leaked in } 2011 \text { would have } \\
\text { precluded therapeutic reference pricing, introduced onerous } \\
\text { obligations for transparency and disclosure, provided more } \\
\text { opportunities for industry influence, enabled decisions to } \\
\text { be appealed and potentially overturned, legalised direct- } \\
\text { to-consumer advertising via the internet and established a } \\
\text { mechanism for ongoing input by US trade officials. At the time } \\
\text { the HIA was conducted, commentary suggested this draft had } \\
\text { been revised and was now more similar to the Australia-US Free } \\
\text { Trade Agreement, but the new draft had not been leaked. }\end{array}$ & $\begin{array}{l}\text { - Corporations may be better equipped to oppose } \\
\text { proposed public health legislation/regulation. } \\
\text { The'healthcare transparency annex' may preclude } \\
\text { use of effective pricing mechanisms and give } \\
\text { companies more leverage in PBS listing decisions. }\end{array}$ \\
\hline Investment* & $\begin{array}{l}\text { Protections for investors (i.e. corporations from one TPP country } \\
\text { that invest in another TPP country). Investments can include } \\
\text { intangibles like intellectual property as well as more tangible } \\
\text { financial investments. } \\
\text { Protections include access to an 'investor-state dispute } \\
\text { settlement' (ISDS) mechanism that allows foreign corporations } \\
\text { to sue governments for monetary compensation outside of } \\
\text { domestic court systems, when they perceive that a policy or law } \\
\text { has harmed their investments. }\end{array}$ & $\begin{array}{l}\text { ISDS may deter countries from introducing and } \\
\text { implementing new healthcare and public health } \\
\text { policies if they have concerns about litigation } \\
\text { (which is very expensive, particularly for smaller } \\
\text { countries and developing countries). } \\
\text { - There are precedents of ISDS cases over public } \\
\text { health issues including tobacco control and patents. }\end{array}$ \\
\hline $\begin{array}{l}\text { Technical barriers to } \\
\text { trade (TBT) }\end{array}$ & $\begin{array}{l}\text { Provisions in TBT chapters are intended to remove or streamline } \\
\text { 'barriers to trade' such as technical regulations and standards } \\
\text { that are applied to imported products (for example, labelling } \\
\text { requirements). The TBT chapter has a number of annexes for } \\
\text { different products, including one for wine and distilled spirits. } \\
\text { No draft text was available for the TBT chapter, but it was } \\
\text { expected to include requirements that technical regulations be } \\
\text { science-based and no more trade-restrictive than necessary. } \\
\text { The annex for wine and distilled spirits was expected to contain } \\
\text { labelling provisions that might make it difficult for governments } \\
\text { to prescribe large front-of-container warning labels. }\end{array}$ & $\begin{array}{l}\text { - TBT provisions may facilitate challenges by } \\
\text { corporations (or by countries on behalf of } \\
\text { corporations) to regulations that have a public } \\
\text { health purpose. } \\
\text { - Provisions in the TBT wine and spirits annex } \\
\text { may limit the ability of countries to stipulate } \\
\text { requirements for health warnings. }\end{array}$ \\
\hline $\begin{array}{l}\text { Cross-border trade } \\
\text { in services }\end{array}$ & $\begin{array}{l}\text { These chapters in trade agreements usually include provisions } \\
\text { related to services, including distribution, marketing, licensing, } \\
\text { etc. The aim is to reduce barriers to trade in services and ensure } \\
\text { that services provided by companies in other countries can } \\
\text { compete on an equal footing with domestic services. } \\
\text { No draft text was available for this chapter, but there were } \\
\text { concerns that provisions might, for example, prohibit bans } \\
\text { or limits on the number and size of services supplied across } \\
\text { borders, which could affect attempts to restrict licenses for } \\
\text { alcohol outlets or inhibit restrictions on alcohol advertising or } \\
\text { marketing of processed foods to children. }\end{array}$ & $\begin{array}{l}\text { - Unless all current and future health services are } \\
\text { explicitly excluded, they are likely to be covered by } \\
\text { these commitments. } \\
\text { - This may reduce the capacity of government } \\
\text { control over regulation of health services and over } \\
\text { services that have an impact on health. }\end{array}$ \\
\hline $\begin{array}{l}\text { Regulatory } \\
\text { coherence* }^{*}\end{array}$ & $\begin{array}{l}\text { Aims to streamline regulation across TPP countries, specifies } \\
\text { how governments go about policy making; includes } \\
\text { consultation and coordination mechanisms. A leaked } \\
\text { draft included requirements for governments to provide } \\
\text { opportunities for stakeholder input into policy-making. }\end{array}$ & $\begin{array}{l}\text { - Could provide a greater role for industry in the } \\
\text { policy making process; a particular concern in } \\
\text { areas where there are conflicts of interest between } \\
\text { corporate and public health goals (e.g. tobacco and } \\
\text { alcohol regulation). }\end{array}$ \\
\hline
\end{tabular}

*Proposals or composite drafts of these chapters/annexes have been leaked and are available in the public domain. It is important to note that many of these proposals and drafts are likely to have been superseded, and that for many chapters there have been no leaks.

${ }^{*}$ Chapters and negotiating areas discussed are limited to those which may impact on the areas considered in the HIA: medicines, tobacco, alcohol, and food. There are additional trade provisions which may have health implications. These are discussed in the HIA report [46].

Figure 2 Trans Pacific Partnership (TTP) chapter, or negotiating area, and possible health implications.

without the use of a publicly available proposal to assess. In the absence of public documents, the HIA used leaked texts indicating potential provisions (figure 2) along with published analysis and commentary, and formulated policy scenarios in order to conduct the assessment and predict potential impacts.
To the best of our knowledge this is the first HIA based on leaked documents, and this is a limitation of the study. Draft chapters leaked during negotiations, to some extent represent the positions put forward by certain parties rather than the final negotiated text. However, in the absence of authorised drafts and 
transparent consultation, the analysis of leaked text has a recognised public interest purpose, ${ }^{26}$ and has been critical in stimulating public debate about the risks associated with proposed provisions.

The scenarios were high-priority future public health policies which could be impacted by the TPP. Scenarios were developed through consultation with a policy expert in each area selected through referral from the steering committees. The final scenarios selected were based on the following criteria:

- The policy scenario is either a current priority or likely to become a priority for Australian health advocacy groups;

- The scenario includes a globally recognised public health intervention with a strong evidence base;

- Based on previous trade agreements, the policy scenario is likely to be impacted by TPP provisions.

The policy scenarios chosen for analysis were: the cost of medicines; restrictions on tobacco advertising; alcohol control measures including restrictions to alcohol availability and advertising, and pregnancy warning labels on alcohol containers; and requirements for food labelling.

The scenarios provided examples of the ways in which the TPP could potentially affect public health policies in Australia, and the subsequent health effects from these impacts. There are many other potential ways that the TPP could impact public health, but due to the secretive nature of the negotiating process and the resource limitations of the HIA, there was no way to determine the scope of all potential policies that could be affected.

\section{Step 3: identification}

Identification is the gathering of data and information about health impacts. For the HIA, we applied a range of methods including: reviewing literature for evidence about the potential impacts of trade agreements on health; accessing national data; consulting with experts; and carrying out an assessment workshop with 20 participants from 4 academic institutions and 10 advocacy organisations. Workshop participants included members of the technical and advocacy advisory committees as well as other key informants identified by the committees. This workshop was crucial to the process, as the participants were able to discuss and agree on the evidence-informed causal pathways for each scoped area and then use this analysis to identify draft recommendations. The process for agreeing on the impacts and identifying recommendations was facilitated through discussion of various questions, including: the plausibility of the impact of the TPP on the policy scenario; the significance of the policy scenario to health; the strength of the evidence; equity considerations (ie, what groups are likely to be most adversely impacted) and recommendations to mitigate potential harms. The final recommendations were subsequently revised and agreed on by all advocacy committee members.

\section{Step 4: assessment}

Assessment involves assessing the information and evidence to predict potential health impacts. After the causal pathways were validated through consultation with stakeholders, the research team characterised the potential impacts on health based on public health literature and stakeholder input. Impact characterisations analyse potential health impacts and characterise the changes according to various indicators. ${ }^{25}$ The following indicators were used to describe the impacts of the TPP. Likelihood-refers to the probability that an impact will occur:

- Speculative: may or may not happen. Plausible, but with limited evidence to support.

- Possible: more likely to happen than not. Direct evidence, but from limited sources.

- Likely: very likely to happen. Direct strong evidence from a range of data sources.

Direction-describes the nature of the effect:

- Positive: impacts that improve or maintain health status.

- Negative: impacts that negatively affect health status.

For each scoped area we identified a causal pathway that linked the potential trade provision being considered in the negotiations to a health outcome. Pathways and health outcomes, supported by the existing literature, were validated with stakeholders through the identification and assessment process. We also considered the potential for differential impacts on various sub-populations.

\section{RESULTS}

Four causal pathways were developed, showing our analysis of impact of the potential TPP provision on the policy scenarios identified (figure 3). In each section below, we describe the policy scenario, the likely impact of TPP provisions under consideration during the negotiations, and the implications of these provisions for health.

\section{Medicines}

Australia's Pharmaceutical Benefits Scheme (PBS) provides public subsidies for prescribed medicines dispensed mainly through community pharmacies. The PBS is important not only for supporting affordable access to medicines, but also for containing healthcare costs and ensuring value for money.

There is sufficient evidence which show that increases in the cost of medicines lead to greater patient copayments through the PBS, ${ }^{27}$ and that increases in patient copayments lead to lower rates of prescription use. ${ }^{28-31}$ Changes to prescription costs impact particularly on vulnerable populations who have less capacity to accommodate increased out-of-pocket expenses such as women, elderly adults, cultural and linguistic minorities, and low-income populations; ${ }^{32} 33$ people with chronic disease, ${ }^{34}$ geographically remote communities $^{35}$ and Aboriginal and Torres Strait Islander populations. $^{33}$

The effect of increased out-of-pocket expenses, particularly for vulnerable populations, has significant impacts on health. Affordability of medicines is a key reason for 


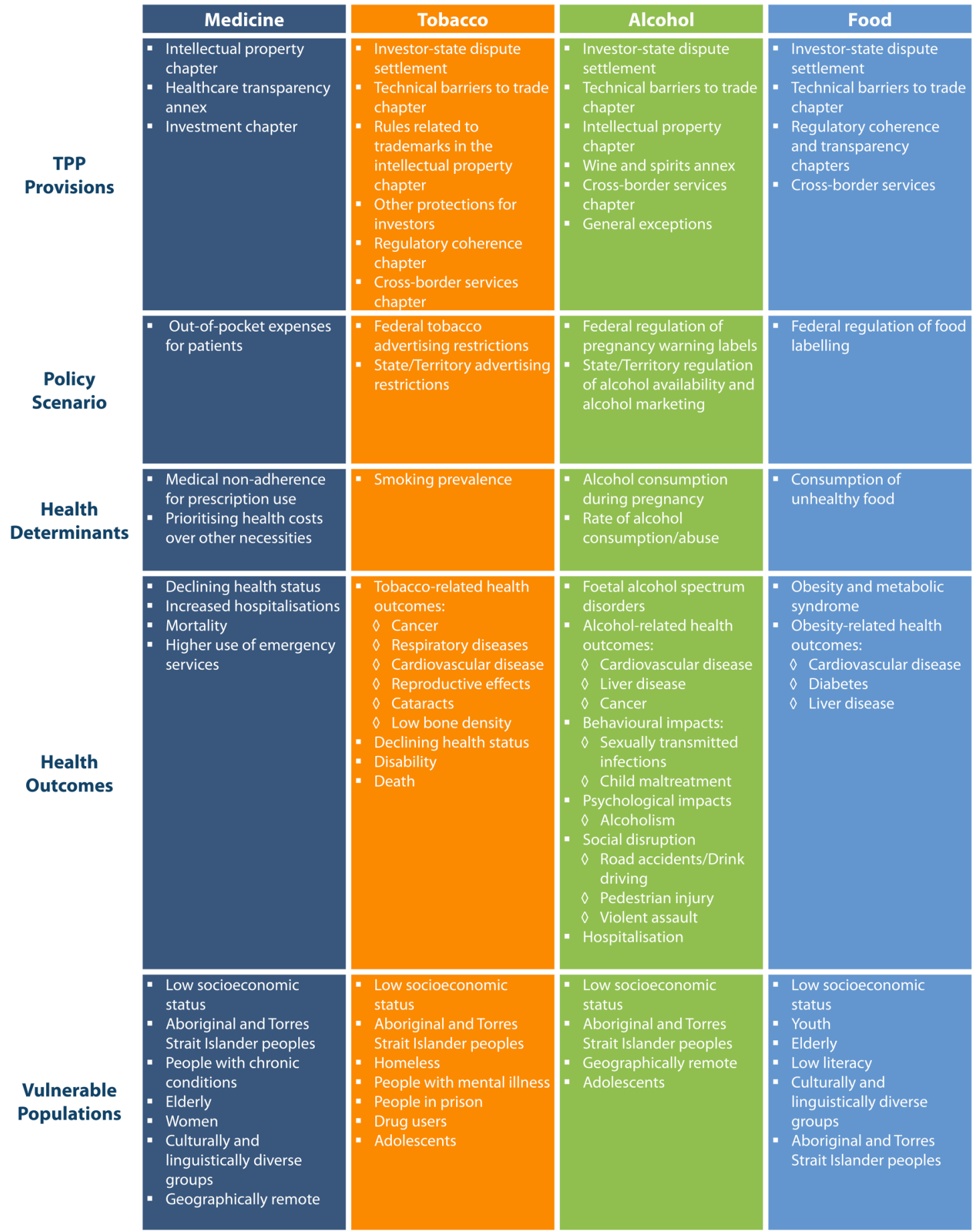

Figure 3 Causal pathways.

non-adherence of prescriptions. ${ }^{36}$ Copayments decrease prescription use; can impact patient medicine use compliance; and can adversely impact disadvantaged populations. $^{37} 38$ Patients with higher cost-sharing for prescriptions have poorer adherence to drug therapy, poorer health outcomes and higher use of emergency services. ${ }^{39-41}$ There is evidence from the USA, that patients with reported medication-cost problems, in addition to underuse, report spending less on necessities such as food, housing and energy costs. ${ }^{42}$
Many provisions proposed for the TPP had the potential to increase the cost of medicines. These were identified in leaked drafts of the intellectual property chapter; ${ }^{43}$ the healthcare transparency annex $;{ }^{44}$ and the investment chapter, ${ }^{45}$ which includes an investor-state dispute settlement (ISDS) mechanism. These provisions are summarised in figure 2 and described in more detail on pages 7-9 in the HIA report. ${ }^{46}$ These provisions, if adopted, could be expected to lead to an increase in the costs of managing the PBS by delaying the availability of 
generic medicines, and constraining the ability of the PBS to contain costs. ${ }^{47-49}$ An increase in the cost of the PBS to government would be likely to lead to higher copayments for patients.

\section{Tobacco control}

There is significant public health evidence that tobacco control strategies are effective at reducing rates of tobacco use. ${ }^{50-52}$ In particular, restrictions on tobacco advertising, such as plain packaging, have led to decreases in rates of smoking. ${ }^{53-60}$ Future legislation will need to maintain current control standards as well as adapt to emerging forms of use, such as electronic nicotine delivery systems, in order continue the downward trend in smoking.

Despite population-level decreases, smoking prevalence has declined least in the most disadvantaged communities. ${ }^{53}$ Smoking rates among Aboriginal and Torres Strait Islander communities are more than double those in the rest of the population ${ }^{61}$ and rates of smoking are also high among homeless people ${ }^{62}$ people who use drugs ${ }^{63}$ incarcerated people, ${ }^{64}$ people with low socioeconomic status, ${ }^{65}$ people with mental illness ${ }^{66}$ and people in rural and remote regions. ${ }^{67}$ Tobacco policies implemented in the past have been effective at decreasing overall rates of smoking, but new and innovative interventions will be needed in the future to affect change in all populations.

Six chapters were identified with potential to limit governments' ability to implement tobacco control policies. The key chapters are: investment, particularly the ISDS mechanism $;{ }^{45}$ rules related to trademarks in intellectual property, ${ }^{43}$ regulatory coherence, ${ }^{68}$ cross-border services $^{69}$ and technical barriers to trade. ${ }^{69}$ These provisions are summarised in figure 2 and described in more detail on page 13 in the HIA report. Multiple chapters may also interact with the potential for amplified effects on tobacco control. ${ }^{70}$ Various provisions in these parts of the TPP may provide the tobacco industry with greater influence over policymaking and more avenues to contest tobacco control measures, as well as preventing governments from introducing new policies. ${ }^{69-73}$

\section{Alcohol policy}

Alcohol control strategies are intended to reduce harm to both the consumer and the broader community. Availability restrictions through limits on alcohol outlet density and trading hours have been shown to be effective at reducing alcohol-related harm. ${ }^{74} 75$ Likewise, restrictions of alcohol advertising in mainstream media, linking alcohol with social and sporting events, and direct marketing campaigns, are considered costeffective approaches to limiting harm in alcohol use. $^{74} 76$ Last, pregnancy warning labels on alcoholic containers is a recommended approach by medical experts to reduce rates of drinking while pregnant, minimising damage to the mother and the fetus. ${ }^{77}$
Certain populations are particularly susceptible to high levels of alcohol use, and are therefore disproportionately affected by a lack of alcohol control policies. Aboriginal and Torres Strait Islander populations ${ }^{78}$ and adolescents $^{74} 79$ have higher rates of alcohol abuse; and alcohol outlet density is higher in low socioeconomic status (SES) populations. ${ }^{80}$ Existing and future alcohol control policies are required to ensure decreased risks of alcohol-related harm for these populations.

There are several ways in which provisions proposed for the TPP may restrict regulation of alcohol marketing, outlet density, and pregnancy warning labels. Specifically, provisions that may impact on alcohol control policies include, among others, those contained in the chapter on technical barriers to trade ${ }^{69}$ the wine and spirits annex; ${ }^{81}$ the cross-border services chapter ${ }^{69}$ and the investment chapter-particularly the ISDS mechanism. ${ }^{45}$ The wine and spirits annex and intellectual property chapter may limit the ability of future governments to require alcohol warning labels, while the cross-border services chapter may prohibit governments from implementing new policies around the restriction of alcohol sales. ${ }^{6981}$ Other provisions, like the technical barriers to trade chapter, and ISDS mechanism, could also hinder development of innovative alcohol control policies. ${ }^{69}$ See figure 2 for summary information about these provisions, and page 16 of the HIA report for further detail. ${ }^{46}$ Any TPP provisions that hinder the ability of government to implement alcohol policies will likely negatively impact health.

\section{Food labelling}

New forms of front-of-pack food labelling have been found to enhance consumer identification of healthy food. ${ }^{82-84}$ As part of a suite of interventions, food labelling is widely regarded as an effective strategy towards decreasing rates of overweight and obesity. ${ }^{77}$ It is also supported by international organisations such as the WHO. ${ }^{85}$

There are disproportionate rates of obesity in low SES, ${ }^{86}$ geographically remote, ${ }^{87}$ culturally and linguistically diverse, ${ }^{86}$ and Aboriginal and Torres Strait Islander populations. ${ }^{87}$ Likewise, many of these same populations are more likely to have difficulty interpreting current food labels, making them more likely to benefit from new interpretative food labelling. ${ }^{88}$

Provisions proposed for the TPP that have the potential to limit implementation of new food labelling requirements in Australia include the ISDS mechanism; ${ }^{45}$ the regulatory coherence chapter ${ }^{68}$ and technical barriers to trade chapter ${ }^{69}$ (see figure 2 and pages 1920 of the HIA report ${ }^{46}$ for further detail). Provisions in these parts of the TPP have the potential to restrict policymakers to regulate using the most effective public health nutrition instruments. ${ }^{1}$ For example, the food industry could argue that introduction of mandatory front-of-pack nutrition labelling would be a technical barrier to trade. ${ }^{2}$ Without strong compensatory 


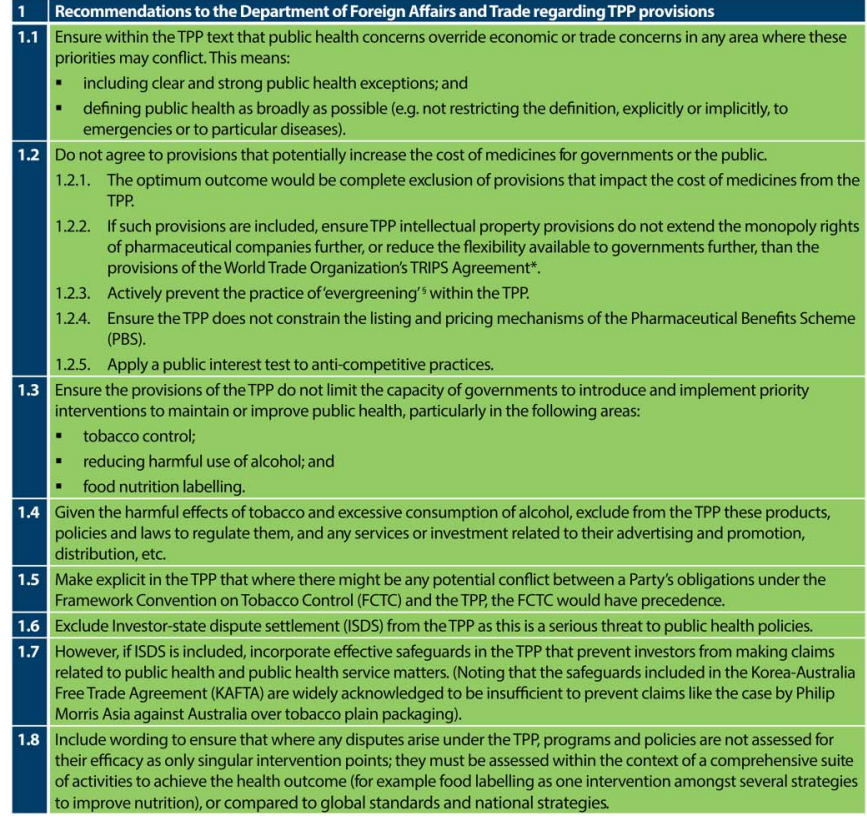

Figure 4 Health impact assessment (HIA) recommendations.

intervention to improve consumer awareness of the relative healthfulness of foods, it is likely that there will be no change to current high rates of obesity, metabolic syndrome and non-communicable diseases. This would have a negative impact on health, particularly for vulnerable populations.

\section{Step 5: HIA recommendations}

In order to mitigate the potential harms identified in the assessment, the HIA team worked with advocacy stakeholders to identify a set of recommendations (figure 4). Recommendations relevant to the specific health policy areas studied in the HIA (medicines, tobacco, alcohol and food labelling) can be found on pages 9, 13, 17 and 20 of the HIA report, respectively. ${ }^{46}$ Recommendations on the specific TPP provisions (such as not including an ISDS mechanism in the agreement) were directed towards the negotiating agency, the Department of Foreign Affairs and Trade (DFAT). They further offered recommendations to DFAT to improve the transparency of the negotiations, such as publication of draft texts and comprehensive public health consultation. It was also recommended that HIA be conducted on the final text of the TPP, but before it is signed by Parliament, as well as being conducted on all future FTAs.

\section{HIA outcomes}

The HIA process effectively engaged policy-relevant stakeholders, contributed to reframing the trade negotiations in relation to their impact on health in the public sphere, and increased the visibility of health in the trade policy agenda. Evidence for this is derived from a range of sources.

The public HIA report was released in March, 2015. ${ }^{46}$ The advocacy advisory committee developed a concerted

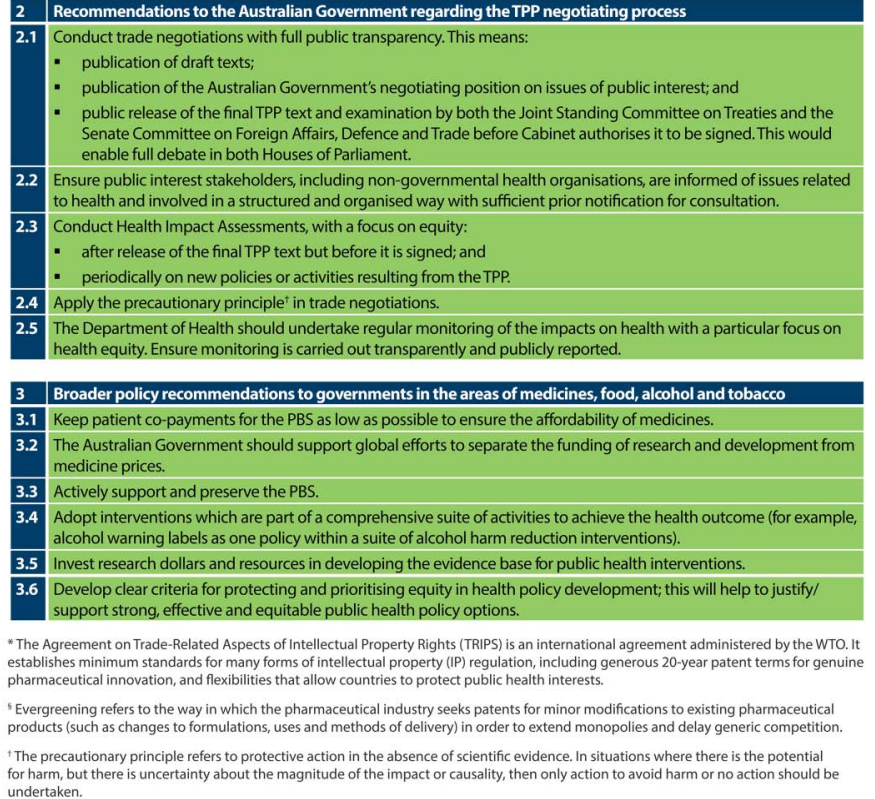

media strategy that included a joint press release which focused on the health findings of the HIA. ${ }^{89}$ In response, over March and April 2015, 50 newspaper articles referenced the HIA and its findings in periodicals from Australia, New Zealand, the USA, Malaysia and Venezuela. In the same time period, steering committee members were interviewed in 26 radio broadcasts, and ABC News conducted a primetime report on the HIA findings that included an interview with the Minister for Trade and Investment, Andrew Robb. ${ }^{90}$ This public engagement was coupled with various social media strategies employed by advocacy committee members such as blog posts, Facebook infographics, and Twitter campaigns. This fed into, and amplified, a public discourse on the trade negotiating process and lack of transparency, ${ }^{91}$ culminating in an inquiry by the Senate Foreign Affairs, Trade and Defence Reference Committee on the trade negotiating process in which the HIA report was used in public testimony. ${ }^{92}$ The HIA report was also submitted directly to the Department of Foreign Affairs and Trade and to the Senate Inquiry. Much of the media engagement and dissemination of the findings were spearheaded by key individuals, such as the CEO of the Public Health Association of Australia (PHAA), who also served as Chair of the Advocacy Advisory Committee, and representatives of the Australian Free Trade and Investment Network (AFTINET) and Choice (the leading Australian consumer advocacy organisation).

The HIA was concluded prior to conclusion of TPP negotiations, allowing time for advocates to use the evidence to inform public debate. While there was little opportunity for direct input to the formal negotiations, public health advocates were able to engage with policymakers through informal channels, using the HIA as technical evidence. 


\section{DISCUSSION}

The findings of the HIA add to a growing body of research evidence suggesting that many TPP provisions proposed during the negotiations are likely to be harmful to health. The study also demonstrated how HIA can be used to bring a range of stakeholders together to systematically identify and examine the potential health impacts of trade agreements while being flexible enough to fit into policymaking and stakeholder time frames. Evidence of the HIA's impact shows that the process effectively engaged policy-relevant stakeholders, contributed to reframing the trade negotiations in relation to their impact on health while increasing the visibility of public health in the trade policy agenda.

The uptake of the HIA in the media suggests that it may be an effective way to engage in the agenda-setting process, in the context of the TPP negotiations in Australia. As Kingdon's 'multiple streams' theory of policymaking highlights, windows of opportunity arise from the intersection of three streams: problem, policy and politics. ${ }^{21}$ The problem stream consists of issues that policymakers and the public want addressed, and that policymakers see as more rather than less solvable. The policy stream comprises ideas that compete to win acceptance by policymakers and their networks based on technical feasibility, value acceptability and resource adequacy, and the type of linkages and integration between different policy actors progressing particular ideas. The politics stream consists of factors such as changes to the national mood, pressure group campaigns, and administrative turnover. Across all these elements are the actions of policy entrepreneurs who are individuals or actors who attempt to couple the streams. When these three streams are coupled or joined together, the opportunity for policy influence is created.

While more detailed analysis of the HIA against these dimensions is required, it is possible to identify the core attributes of the process which allowed the HIA to contribute to progressing each of these streams, increasing the possibility of a 'policy window' opening.

Concerning the problem stream, the HIA's systematic synthesis of the evidence provided compelling and timely evidence of the problem during the negotiating period, and created a detailed assessment of the effect that proposed provisions could be expected to have on the health of Australians.

Concerning the policy stream, the recommendations of the HIA report were intended to provide a set of concrete policy solutions for addressing and mitigating the effects of the TPP on health. The specific policy recommendations for the Australian Government are a point of difference from other academic work outlining more general policy issues and potential policy options at a global level. These have the potential to be much more relevant to policymakers, as they identified feasible and effective strategies (thus addressing known concerns of policymakers) to modify the TPP at the negotiation stage to improve the Agreement with respect to health.
Concerning the politics stream, the HIA also gave consideration to the politics of trade policymaking and, in particular, the timing of the TPP negotiations and the players involved. By conducting the HIA prior to the finalisation of the negotiations, advocacy stakeholders could engage with the media, DFAT and members of parliament to discuss the findings of the HIA. The process engaged a wide range of policy-relevant stakeholders and was able to engage with the political dialogue via public media outlets and through formal submission and Senate Committee public testimony.

Concerning policy entrepreneurs, we also observed some individuals acting as policy entrepreneurs in coordinating the process, effectively bringing these three streams together and ensuring that the HIA was taken up by the media and fed into policymaking forums. They played an important role in creating the policy window which allowed the HIA findings to receive significant public and policy attention; in this way, they can be seen as policy entrepreneurs. ${ }^{21}$ These included the CEO of the PHAA, and representatives of AFTINET and Choice. ${ }^{93}$

The final text of the TPP was released in November 2015. It is likely that the text of the final agreement will be scrutinised for some time yet, with experts considering what the long-term implications will be. Preliminary assessment of the final text suggests that some of the more harmful provisions have been mitigated, but concerns remain. Two examples are provided below.

The final pharmaceutical provisions are sufficiently similar to the Australia-US Free Trade Agreement, that they are unlikely to require any change to Australian law or the operation of the PBS. ${ }^{94}$ It seems likely that the HIA and associated media coverage and advocacy contributed to growing awareness of, and political opposition to, proposals to extend monopolies through the TPP, which assisted in strengthening the Australian Government's resistance to the US proposals. These provisions may, however, impact adversely on other countries, particularly developing countries. Provisions related to biologics-a form of medicine derived from living products-are sufficiently ambiguous to allow for interpretations that could risk the USA trying to enforce 8 years of market exclusivity versus the 5 years currently required in Australia. ${ }^{95}$

The final agreement also included an optional tobacco carve-out from ISDS, allowing TPP countries to prevent the use of ISDS to challenge tobacco control measures. Yet even these apparent 'wins' have some limitations. Unlike tobacco, the health system, food and alcohol were not carved out from ISDS, leaving these policy areas vulnerable to claims by foreign investors. While various safeguards have been included to try and protect public health, experts have raised doubts about whether they will be sufficient. ${ }^{9697}$

\section{CONCLUSION}

The HIA found that a range of provisions proposed for the TPP during the negotiations had the potential to 
negatively impact the health of Australians, particularly for disadvantaged population groups. Provisions proposed for the TPP may increase the cost of medicines and prevent or impede the adoption of effective public health policies to regulate tobacco, alcohol and processed foods. While the outcomes for public health are mixed, many of the more harmful provisions were mitigated to some extent prior to the conclusion of the negotiations. To a large degree, the outcomes in key areas (such as biological medicines and tobacco control) have been credited to the Australian Government's refusal to bow to pressure from the USA during the final stages of the negotiations. It seems likely that the HIA findings and the public debate it stimulated made a contribution to this resolve.

Findings suggest that HIA provides a useful method for reviewing and synthesising evidence, and predicting likely policy and health impacts in the context of trade negotiations. HIA, in this case, was particularly useful for mobilising advocacy and creating a window of opportunity that drew public attention to the health issues at stake in the TPP negotiations in an unprecedented way.

It is important to note that a prospective HIA based on proposed provisions during the negotiation process (in the context of limited information) does not hold the same value as a comprehensive HIA on publicly available text of the TPP. One of the recommendations of the HIA was that an equity-focused HIA be conducted on the final text of the TPP before it is signed.

\author{
Author affiliations \\ ${ }^{1}$ Centre for Health Equity Training, Research and Evaluation, University of New \\ South Wales, A Member of the Ingham Institute, Liverpool, New South Wales, \\ Australia \\ ${ }^{2}$ School of Psychology and Public Health, La Trobe University, Melbourne, \\ Victoria, Australia \\ ${ }^{3}$ Menzies Centre for Health Policy, University of Sydney, Sydney, New South \\ Wales, Australia \\ ${ }^{4}$ RegNet School of Regulation and Global Governance, Australian National \\ University, Canberra, Australian Capital Territory, Australia
}

Twitter Follow Katherine Hirono at @KatieHirono

Acknowledgements The following organisations contributed greatly to the health impact assessment through their participation on the advocacy advisory committee: Australian Federation of AIDS Organisations, Australian Health Promotion Association, Australian Healthcare and Hospitals Association, Australian Medical Students Association, Consumer's Health Forum, Doctors Reform Society, Foundation for Alcohol Research and Education, Médecins Sans Frontières Australia, Mental Health Council of Australia, NSW Nurses and Midwives Association, Public Health Association of Australia-Chair.

Contributors $\mathrm{KH}, \mathrm{FH}, \mathrm{DG}, \mathrm{PH}$ and AMT conceived of and designed the study. $\mathrm{KH}$ and $\mathrm{DG}$ collected the data used in the study. $\mathrm{KH}, \mathrm{FH}, \mathrm{DG}, \mathrm{PH}, \mathrm{AMT}$ and $\mathrm{SF}$ analysed the data. $\mathrm{KH}, \mathrm{FH}, \mathrm{DG}, \mathrm{PH}, \mathrm{AMT}$ and $\mathrm{SF}$ interpreted the results of the data analysis. KH, FH and DG drafted the manuscript. KH, FH, DG, PH, AMT and SF provided critical intellectual revisions. All the authors read and approved the final submitted version of the manuscript, and accept accountability for all aspects of the work. All authors included on this paper fulfil the criteria of authorship. No one else who fulfils the criteria of authorship has been excluded as an author.
Funding This research received no specific grant from any funding agency in the public, commercial or not-for-profit sectors.

Competing interests DG received funding from the Australian Research Council for research on the TPP, health and nutrition; DG has received funding from various national and international non-government organisations to attend speaking engagements related to trade agreements and health, including the TPP; DG has represented the Public Health Association of Australia on matters related to the TPP; PH receives funding from the Australian National Health and Medical Research Centre, the Australian Research Council, and the Henry Halloran Trust at the University of Sydney; AMT received funding from the Australian Research Council for research on the TPP, health and nutrition; SF received funding from the Australian Research Council for research on the TPP, health and nutrition; no other relationships or activities that could appear to have influenced the submitted work.

Competing interests None declared.

Provenance and peer review Not commissioned; externally peer reviewed.

Data sharing statement No additional data are available.

Open Access This is an Open Access article distributed in accordance with the Creative Commons Attribution Non Commercial (CC BY-NC 4.0) license, which permits others to distribute, remix, adapt, build upon this work noncommercially, and license their derivative works on different terms, provided the original work is properly cited and the use is non-commercial. See: http:// creativecommons.org/licenses/by-nc/4.0/

\section{REFERENCES}

1. Friel S, Gleeson D, Thow AM, et al. A new generation of trade policy: potential risks to diet-related health from the trans pacific partnership agreement. Global Health 2013;9:46.

2. Thow AM, Snowdon W, Labonté R, et al. Will the next generation of preferential trade and investment agreements undermine prevention of noncommunicable diseases? A prospective policy analysis of the Trans Pacific Partnership Agreement. Health Policy 2015;119:88-96.

3. Baum FE, Anaf JM. Transnational corporations and health: a research agenda. Int $J$ Health Serv 2015;45:353-62.

4. Gleeson D, Friel S. Emerging threats to public health from regional trade agreements. Lancet 2013;381:1507-9.

5. Department of Foreign Affairs and Trade (DFAT). Trans-Pacific Partnership Agreement Overview. http://www.dfat.gov.au/fta/tpp/ tpp-overview.pdf

6. Unitaid. The trans-pacific partnership agreement: implications for access to medicines and public health. Genenva: Unitaid World Health Organisation, 2014.

7. Australian Medical Association. TPP fears despite Govt assurances. 2015. https://ama.com.au/ausmed/tpp-fears-despite-govt-assurances

8. Medecins Sans Frontieres. Briefing note: Trading away health: The Trans-Pacific Partnership Agreement (TPP) 2015. 2015. http://www. msfaccess.org/content/briefing-note-trading-away-health-transpacific-partnership-agreement-tpp-2015

9. Office of the High Commissioner for Human Rights. UN experts voice concern over adverse impact of free trade and investment agreements on human rights 2 June 2015. http://www.ohchr.org/EN/ NewsEvents/Pages/DisplayNews.aspx?NewsID $=16031$ \& LanglD=E@

10. Harris $P$, Gleeson D. Assessing the impact of the Trans-Pacific Partnership Agreement on the health of Australians. Aust N Z J Public Health 2014;38:496-6.

11. World Health Organisation (WHO). Closing the gap in a generation. Geneva: Comission on Social Determinants of Health, 2008.

12. Bacigalupe A, Esnaola S, Martín U, et al. Learning lessons from past mistakes: how can Health in All Policies fulfil its promises? $J$ Epidemiol Community Health 2010;64:504-5.

13. Collins J, Koplan JP. Health impact assessment: a step toward health in all policies. JAMA 2009;302:315-17.

14. Haigh F, Baum F, Dannenberg AL, et al. The effectiveness of health impact assessment in influencing decision-making in Australia and New Zealand 2005-2009. BMC Public Health 2013;13:1188.

15. Kemm J. Past achievement, current understanding and future progress in health impact assessment. Oxford: Oxford University press, 2013.

16. Haigh F, Harris E, Chok HNG, et al. Characteristics of health impact assessments reported in Australia and New Zealand 2005-2009. Aust N Z J Public Health 2013;37:534-46. 
17. Blau J, Ernst K, Wismar M, et al. The use of health impact assessment across Europe. In: Ståhl T, Wismar M, Ollila E, et al., eds. Health in all policies: prospects and potentials. Helsinki: Ministry of Social Affairs and Health, 2006:209-30.

18. Dannenberg AL, Bhatia R, Cole BL, et al. Use of health impact assessment in the U.S: 27 case studies, 1999-2007. Am J Prev Med 2008;34:241-56.

19. Pope J, Bond A, Morrison-Saunders A, et al. Advancing the theory and practice of impact assessment: setting the research agenda. Environ Impact Assesst Rev 2013;41:1-9.

20. Harris-Roxas B, Harris E. Differing forms, differing purposes: a typology of health impact assessment. Environ Impact Assess Rev 2011;31:396-403.

21. Kingdon JW, Thurber JA. Agendas, alternatives, and public policies. 2nd edn. Pearson, 2010.

22. Shiffman J, Smith S. Generation of political priority for global health initiatives: a framework and case study of maternal mortality. Lancet 2007;370:1370-9.

23. Buse K, Mays N, Walt G. Making health policy. McGraw-Hill Education (UK), 2012.

24. Harris $P$, Sainsbury $P, K e m p ~ L$. The fit between health impact assessment and public policy: practice meets theory. Soc Sci Med 2014;108:46-53.

25. Harris P, Harris-Roxas B, Harris E, et al. Health Impact Assessment: A practical guide. Sydney: Centre for Health Equity Training, Research and Evaluation, Part of the UNSW Research Centre for Primary Health Care and Equity, 2007, pp 13-17.

26. Flynn S, Baker B, Kaminski M, et al. The U.S. proposal for an intellectual property chapter in the trans-pacific partnership agreement. Am University Int Law Rev 2012;28:105-202.

27. Department of Health and Ageing-Medicines Australia. Trends in and drivers of Pharmaceutical Benefits Scheme expenditure: Report for the Access to Medicines Working Group. Department of Health and Ageing, 2013.

28. Lehnbom EC, Boxall A-M, Russell LM, et al. Management of medicines in chronic illness: views of community pharmacists in New South Wales. Journal of Pharmacy Practice \& Research 2009;39: 207-10

29. Schoen C, Osborn R, How SK, et al. In chronic condition: experiences of patients with complex health care needs, in eight countries, 2008. Health Aff (Millwood) 2009;28:w1-w16.

30. Searles A, Doran E, Faunce TA, et al. The affordability of prescription medicines in Australia: are copayments and safety net thresholds too high? Aust Health Rev 2013;37:32-40.

31. Doran E, Robertson J, Salkeld G. Pharmaceutical Benefits Scheme cost sharing, patient cost consciousness and prescription affordability. Aust Health Rev 2011;35:37-44.

32. Jatrana S, Crampton P, Norris P. Ethnic differences in access to prescription medication because of cost in New Zealand. $J$ Epidemiol Community Health 2011;65:454-60.

33. Kemp A, Roughead E, Preen D, et al. Determinants of self-reported medicine underuse due to cost: a comparison of seven countries. $J$ Health Serv Res Policy 2010;15:106-14.

34. Essue B, Kelly P, Roberts M, et al. We can't afford my chronic illness! The out-of-pocket burden associated with managing chronic obstructive pulmonary disease in western Sydney, Australia. $J$ Health Serv Res Policy 2011;16:226-31.

35. Stocks N, Ryan P, Allan J, et al. Gender, socioeconomic status, need or access? Differences in statin prescribing across urban, rural and remote Australia. Aust J Rural Health 2009;17:92-6.

36. Gadkari AS, McHorney CA. Medication nonfulfillment rates and reasons: narrative systematic review. Curr Med Res Opin 2010;26:683-705.

37. Kiil A, Houlberg K. How does copayment for health care services affect demand, health and redistribution? A systematic review of the empirical evidence from 1990 to 2011. Eur J Health Econ 2014:15:813-28.

38. Hynd A, Roughead EE, Preen DB, et al. The impact of co-payment increases on dispensings of government-subsidised medicines in Australia. Pharmacoepidemiol Drug Saf 2008;17:1091-9.

39. Hsu J, Price M, Huang J, et al. Unintended consequences of caps on Medicare drug benefits. N Engl J Med 2006;354:2349-59.

40. Mojtabai R, Olfson M. Medication costs, adherence, and health outcomes among Medicare beneficiaries. Health Affairs 2003;22:220-9.

41. Heisler M, Langa KM, Eby EL, et al. The health effects of restricting prescription medication use because of cost. Med Care 2004;42:626-34.

42. Piette JD, Rosland AM, Silveira MJ, et al. Medication cost problems among chronically ill adults in the US: did the financial crisis make a bad situation even worse. Patient Prefer Adherence 2011;5:187-94.
43. Trans Pacific Partnership. Intellectual Property [Rights] Chapter: Consolidated Text. Ho Chi Minh Round-May 16, 2014. [Leaked draft text]. Ho Chi Minh Round-May 16, 2014. [Leaked draft text]. 2014. https://wikileaks.org/tpp-ip2/tpp-ip2-chapter.pdf

44. Trans Pacific Partnership. Transparency chapter-annex on transparency and procedural fairness for healthcare technologies [Leaked draft text]. 2011. http://www.citizenstrade.org/ctc/wp-content/ uploads/2011/10/TransPacificTransparency.pdf

45. Trans Pacific Partnership. Investment chapter [Leaked draft text]. 2012. http://www.citizenstrade.org/ctc/wp-content/uploads/2012/06/ tppinvestment.pdf

46. Hirono K, Haigh F, Gleeson D, et al. Negotiating healthy trade in Australia: health impact assessment of the proposed Trans-Pacific Partnership Agreement. Liverpool, NSW: Centre for Health Equity Training Research tand Evaluation, part of the Centre for Primary Health Care and Equity, UNSW Australia, 2015.

47. Lopert R, Gleeson D. The high price of "free" trade: U.S. trade agreements and access to medicines. J Law Med Ethics 2013;41:199-223.

48. Flynn S, Baker B, Kaminski M, et al. The U.S. Proposal for an Intellectual Property Chapter in the Trans-Pacific Partnership Agreement. American University International Law Review. 2012;28:105-202

49. Médecins Sans Frontières. Trading Away Health: The Trans-Pacific Partnership Agreement (TPP). 2013. http://www. doctorswithoutborders.org/publications/reports/2013/Access Briefing_TPP_ENG_2013.pdf

50. Clarke $\mathrm{H}$, Prentice $\bar{D}$. Will plain packaging reduce cigarette consumption? Economic papers. J Appl Econ Policy 2012;31:303-17.

51. AlHW (Australian Institute of Health and Welfare). 2010 National drug strategy household survey report. 2011. http://www.aihw.gov. au/WorkArea/DownloadAsset.aspx?id=10737421314

52. ABS (Australian Bureau of Statistics). Australian Health Survey: first results, 2011-12. Canberra: ABS, 2012.

53. Tobacco Working Group. The Healthiest country by 2020 , Technical Report 2, Tobacco Control in Australia: making smoking history. Australia: National Preventative Health Taskforce, 2009.

54. Hammond D, Fong GT, McDonald PW, et al. Impact of the graphic Canadian warning labels on adult smoking behaviour. Tob Control 2003;12:391-5

55. Azagba S, Sharaf MF. The effect of graphic cigarette warning labels on smoking behavior: evidence from the Canadian experience. Nicotine Tob Res 2013;15:708-17.

56. Hammond D, Fong GT, McNeill A, et al. Effectiveness of cigarette warning labels in informing smokers about the risks of smoking: findings from the International Tobacco Control (ITC) Four Country Survey. Tob Control 2006;15(Suppl 3):iii19-25.

57. Moodie CS, Mackintosh AM. Young adult women smokers' response to using plain cigarette packaging: a naturalistic approach. $B M J$ Open 2013;3:pii: e002402.

58. Wakefield MA, Hayes L, Durkin S, et al. Introduction effects of The Australian plain packaging policy on adult smokers: a cross-sectional study. BMJ Open 2013;3:pii: e003175.

59. Hammond D, Dockrell M, Arnott D, et al. Cigarette pack design and perceptions of risk among UK adults and youth. Eur J Public Health 2009;19:631-7.

60. Quit Victoria. Plain packaging of tobacco products: a review of the evidence. Cancer Council Victoria, 2011.

61. Indigenous and Remote Health Division, Australian Department of Health. Aboriginal and Torres Strait Islander Health Performance Framework (HPF). 2012. http://www.health.gov.au/internet/ publications/publishing.nsf/Content/oatsih-hpf-2012-toc tier2 hlthbeh 215

62. Kermode $\mathrm{M}$, Crofts $\mathrm{N}$, Miller $\mathrm{P}$, et al. Health indicators and risks among people experiencing homelessness in Melbourne, 19951996. Aust N Z J Public Health 1998:22:464-70.

63. Stafford J, Sindicich N, Burns L, et al. Australian Drug Trends 2008: Findings from the Illicit Drug Reporting Systems (IDRS). Sydney: National Drug and Alcohol Research Centre, University of New South Wales, 2009.

64. Australian Institute of Health and Welfare. The health of Australia's prisoners 2010. Canberra: AlHW; 2011.

65. AlHW (Australian Institute of Health and Welfare). Drugs in Australia 2010: tobacco, alcohol and other drugs. Drug statistics series, ed. Canberra: AlHW, 2011

66. Australian Bureau of Statistics. National survey of mental health and wellbeing: summary of results, 2007. Canberra: ABS; 2008. ABS publication 4326.0.

67. Australian Institute of Health and Welfare. 2010 National drug strategy household survey report. Canberra: AlHW, 2011. 
68. Trans Pacific Partnership. Trans-Pacific Partnership (TPP) Regulatory Coherence [Leaked draft text]. 2010. http://www. citizenstrade.org/ctc/wp-content/uploads/2011/10/ TransPacificRegulatoryCoherence.pdf

69. Kelsey J. New-generation free trade agreements threaten progressive tobacco and alcohol policies. Addiction 2012;107:1719-21.

70. Kelsey J. The Trans-Pacific Partnership agreement: a gold-plated gift to the global tobacco industry? Am J Law Med 2013;39:237-64.

71. Porterfield M, Byrnes C. Philip Morris v. Uruguay: Will investor-State arbitration send restrictions on tobacco marketing up in smoke? Investment Treaty News [newspaper online]. 12 July, 2011. Available from: http://www.iisd.org/itn/2011/07/12/philip-morris-v-uruguay-willinvestor-state-arbitration-send-restrictions-on-tobacco-marketing-upin-smoke/

72. Fooks G, Gilmore AB. International trade law, plain packaging and tobacco industry political activity: the Trans-Pacific Partnership. Tob Control 2014;23:e1.

73. Stumberg R. Safeguards for tobacco control: options for the TPPA. Am J Law Med 2013;39:382-441.

74. Anderson P, Chisholm D, Fuhr DC. Effectiveness and costeffectiveness of policies and programmes to reduce the harm caused by alcohol. Lancet 2009;373:2234-46.

75. Martineau F, Tyner E, Lorenc T, et al. Population-level interventions to reduce alcohol-related harm: an overview of systematic reviews. Prev Med 2013;57:278-96.

76. Cobiac L, Vos T, Doran C, et al. Cost-effectiveness of interventions to prevent alcohol-related disease and injury in Australia. Addiction 2009;104:1646-55.

77. Blewett N. Labelling Logic: review of food labelling law and policy (2011). Department of Health and Ageing, 2011.

78. AlHW (Australian Institute of Health and Welfare). National Drug Strategy Household Survey 2013. Canberra, AlHW, 2013.

79. Jones SC, Gordon R. Regulation of alcohol advertising: Policy options for Australia. Evidence Base 2013;2:1-37.

80. Livingston M, Chikritzhs T, Room R, et al. Changing the density of alcohol outlets to reduce alcohol-related problems. Drug Alcohol Rev 2007;26:557-66.

81. O'Brien PL, Gleeson DH. Retaining our right to regulate alcohol warnings. Med J Aust 2013;199:447-7.

82. Kelly B, Hughes C, Chapman K, et al. Consumer testing of the acceptability and effectiveness of front-of-pack food labelling systems for the Australian grocery market. Health Promot Int 2009;24:120-9.

83. Chapman K. Out with traffic lights, in with stars-next steps for food labelling. http://www.cancercouncil.com.au/65841/news-media/blog/ healthy-living-cancer-prevention/out-with-traffic-lights-in-with-stars-\% E2\%80\%93-next-steps-for-food-labelling-by-kathy-chapman/
84. Campos S, Doxey J, Hammond D. Nutrition labels on pre-packaged foods: a systematic review. Public Health Nutr 2011;14: 1496-506.

85. World Health Organization (WHO). Global strategy, on diet, physical activity and health. World Health Organization, 2004.

86. Ford PB, Dzewaltowski DA. Disparities in obesity prevalence due to variation in the retail food environment: three testable hypotheses. Nutr Rev 2008;66:216-28.

87. Australian National Preventative Health Agency. Promoting a healthy Australia: Smoking and disadvantage [evidence brief]. Canberra: ANPHA; 2013.

88. Yeatman $\mathrm{H}$, van der Want E. Food labelling and its influences on food choices [evidence brief]. Deakin: Deeble Institute for Health Policy Research; 2012 p. 1-6. Available from: h https://ahha.asn.au/ sites/default/files/docs/policy-issue/20120615_deeble_institute evidence_brief_food_labelling.pdf

89. Public Health Association of Australia. Report finds medicine affordability, public health policies at risk in Trans Pacific Partnership [media release] 3 March 2015. https://www.phaa.net.au/documents/ item $/ 512$

90. Drysdale K. Trans-Pacific Partnership-how do we make sense of the TPP secret negotiations? ABC, 2015.

91. Brisbane Times. Trans Pacific Partnership poses grim risks: Fairfax Media [newspaper online], 3 March 2015. http://www.brisbanetimes. com.au/video/video-news/video-federal-politics/trans-pacificpartnership-poses-grim-risks-20150302-3rb85

92. Senator Wyden (OR). On introduction of the Congressional Oversight of Trade Negotiations Act. Congressional Record 66 (23 May 2012) p S3517. http://thomas.loc.gov/cgi-bin/query/D?r112:66:./ temp/ r1129vJddO::

93. Kehoe J. US, Australia drug dispute is holding up settlement of the Trans Pacific Trade Deal. Australia Financial Review 20154 Oct. http:// www.afr.com/news/politics/national/us-australia-drug-dispute-isholding-up-settlement-of-the-trans-pacific-trade-deal-20151003-gk0r65

94. Department of Foreign Affairs and Trade (DFAT). Trans-Pacific Partnership Agreement Outcomes: Health. 2016. http://dfat.gov.au/ trade/agreements/tpp/outcomes-documents/Pages/outcomes-health. aspx

95. Gleeson D. Biologics provisions in the final TPP text. 2015. http:// itsourfuture.org.nz/wp-content/uploads/2015/11/Biologics-provisionsin-the-final-TPP-text.pdf

96. Kawharu A. Expert Paper \#2 TPPA: Chapter 9 on Investment. 2015 https:/tpplegal.files.wordpress.com/2015/12/ep2-amokura-kawharu.pdf

97. Johnson L, Sachs L. The TPP's Investment Chapter: Entrenching, Rather than Reforming, a Flawed System. http://ccsi.columbia.edu/ 2015/11/18/the-tpps-investment-chapter-entrenching-rather-thanreforming-a-flawed-system/ 